\title{
PENGGUNAAN SARINGAN KERAMIK TYPE CLYPOT DALAM UPAYA PENYEDIAAN AIR BERSIH DI KAWASAN PESISIR KUWARU, SRANDAKAN, KABUPATEN BANTUL
}

\author{
Sri Haryanti P 1), Edy Masduqi ${ }^{2)}$ \\ 1) 2) Fakultas Teknologi Sumber Daya Alam, Institut Teknologi Yogyakarta \\ email: sriharyanti@ity.ac.id ${ }^{1)}$
}

\begin{abstract}
ABSTRAK
Penyediaan air bersih harus memenuhi persyaratan yang diatur Peraturan Menteri Kesehatan RI N0.492/Menkes/Per/IV2010 kualitas air minum. Metode yang digunakan dalam penelitian ini adalah metode penelitian eksperimental. Pengambilan sampel dilakukan di Pesisir Pantai dan Dusun Kuwaru yaitu satu sampel dari sumur di Pantai Kuwaru, 2 sampel lagi diambil di Dusun Kuwaru. Dari ketiga sampel tersebut dilkaukan pengujian laboratorium terhadap parameter kualitas air sebelum dan sesudah disaring/difiltarsi dengan filter keramik Hasil pengujian kualitas air dibandingankan dengan kualitas standar air minum menurut Permenkes No.492/2010.

Penyaringan dengan saringan keramik jenis claypot yang memiliki keamampuan merembeskan air 5 liter dalam waktu $3 \mathrm{jam}$ atau kecepatan permeabilitas 1,667 lt/jam. Hasil penyaringan dengan filter keramik menunjukkan perubahan terhadap warna dan bau, dimana air hasil penyaringan lebih jernih dan tidak berbau. Sedangkan dari hasil uji kualitas air di laboratorium jika dibandingkan dengan standar air minum Permenkes no 492/2010 menunjukkan bahwa, kadar kekeruhan , TDS,Ph , Nitrat, Nitrit, Kesadahan, Zat Organik sebelum disaring/difiltrasi denganfilter keramik berada di atas ambang batas maksimal kadar yang ditentukan setelah disaring/difiltrasi beberapa parameter menunjukkan kadar di bawah ambang batas maksimal. Khusus untuk parameter Besi $(\mathrm{Fe})$ tidak mengalami perubahan kadar sebelum dan sesudah penyaringan masih di atas ambang batas. Untuk parameter biologi yaitu parameter e-coli dan coliform setelah disaring turun drastis dari $>2400$ MPN/100 menjadi >3 MPN/100 meskipun masih di atas ambang batas yaitu 0 .
\end{abstract}

Kata kunci: Air Bersih, Filter Keramik, Pengolahan Air

\section{USING TYPE CLYPOT CERAMIC FILTERS IN THE PROVISION OF CLEAN WATER IN COASTAL AREA KUWARU, SRANDAKAN, BANTUL REGENCY}

ABSTRACT
Provision of clean water must meet the requirements set by the Regulation of the Minister of Health N0.492 / Menkes / Per / IV2010 drinking water quality. The method used in this study is an experimental research method. Sampling was carried out at Peisir Pantai and Kuwaru Hamlet, namely one sample from a well at Kuwaru Beach, 2 more samples were taken at Kuwaru Hamlet. Of the three samples, laboratory tests were carried out on water quality parameters before and after filtering / filtering with ceramic filters. The results of water quality testing were compared with drinking water quality standards according to Permenkes No.492 / 2010.

Filtering with claypot ceramic filter has the ability to absorb 5 liters of water in 3 hours or permeability speed of 1,667 lt / hour. Filtering results with ceramic filters show changes in color and odor, where the filtered water is clearer and odorless. While the results of water quality testing in the laboratory when compared with the standard of drinking water Permenkes no 492/2010 shows that, turbidity levels, TDS, Ph, Nitrate, Nitrite, Hardness, Organic Substances before being filtered / filtered with ceramic filters are above the maximum threshold level determined after filtered / filtered several parameters indicate levels below the maximum threshold. Especially for the parameter Iron $(\mathrm{Fe})$ did not experience changes in levels before and after filtering is still above the threshold. For biological parameters namely e-coli and coliform parameters after being filtered it dropped dramatically from > $2400 \mathrm{MPN} / 100$ to> $3 \mathrm{MPN} / 100$ even though it was still above the threshold of 0 .

Keywords: Clean water, Ceramik filter, Water Treatment

\section{PENDAHULUAN}

Air adalah kebutuhan esensial bagi hidup dan kehidupan manusia serta tidak dapat tergantikan keberadaan maupun fungsinya, maka ketersediaan air bersih yang memenuhi persyaratan mutlak diperlukan. Penyediaan air bersih merupakan salah satu permasalahan krusial dunia termasuk di 
Indonesia karena air tidak lagi menjadi sumber alam yang melimpah dan murah saat ini. Kebutuhan air bersih dapat terpenuhi dengan memanfaatkan airtanah dimana air tanah menjadi sumber air yang paling banyak digunakan oleh penduduk dalam beraktivitas (Santosa dan Adji, 2014).

Berdasarkan pengamatan di lokasi, sarana prasarana sanitasi khususnya air bersih yang memenuhi persyaratan belum dikembangkan. Keluhan yang disampaikan berkaitan dengan air bersih adalah air yang berbau amis, keruh/ berwarna kekuningan atau awalnya air jernih setelahdibiarkan ada endapan kuning kecoklatan, dan adanya noda-noda pada peralatan saniter.

\section{TINJAUAN PUSTAKA \\ Kualitas Air}

Kualitas air merupakan karakteristik mutu yang dibutuhkan dalam pemanfaatan air sesuai dengan yang diperuntukannya. Pengujian kualitas air yang biasa dilakukan adalah uji kimia, fisik, biologi, atau uji kenampakan (bau dan warna). Air yang digunakan untuk kebutuhan hidup sehari-hari khususnya untuk.penyediaan air bersih harus memenuhi persyaratan yang diatur Peraturan Menteri Kesehatan RI N0.492/Menkes/Per/IV2010 kualitas air mnum dapat ditinjau dari: Parameter fisik ( bau, kekeruhan, rasa, suhu, warna dan jumlah Total Suspended Solid (TSS)Total suspended atau padatan tersuspensi dan TDS (Total Dissolved Solid), Parameter Kimia yang antara lain PH, BOD, COD, Fe, Mn dan salinitas , Parameter Biologi (Coliform dan E-Coli)

Parmeter fisik dapat diidentifikasikan dari kondisi fisik air. Air yang baik idealnya tidak berbau, tidak memiliki rasa/tawar, dan suhu ideal untuk air minum sekitar 30 o C. Menurut Effendy (2003), suhu dari suatu badan air dipengaruhi oleh musim, lintang (latitude), ketinggian dari permukaan laut, waktu dalam hari, sirkulasi udara, penutupan awan dan aliran serta kedalaman. Total suspended Suspended Solid (TSS) atau padatan tersuspensi yang menyebabkan kekeruhan air, tidak terlarut dan tidak dapat mengendap. Partikel menurunkan intensitas cahaya yang tersuspensi dalam air TDS (Total Dissolved Solid), atau total padatan terlarut merupakan bahan dalam air yang dapat melewati filter 2,0 mikrometer atau lebih kecil ukuran rata-rata nominal pori. $2^{0}$ celcius. Total padatan terlarut merupakan konsentrasi jumlah ion kation (bermuatan positif) dan anion (bermuatan)

Parameter Kimia dapat diukur secara insitu atau diujikan: Derajat keasaman $(\mathrm{pH})$ air yang lebih kecil dari 6,5 atau $\mathrm{pH}$ asam meningkatkan korosifitas pada benda-benda logam, menimbulkan rasa tidak enak dan dapat menyebabkan beberapa bahan kimia menjadi racun yang mengganggu kesehatan (Sutrisno, 2006). Salinitas, adalah konsentrasi seluruh larutan garam yang diperoleh dalam air laut. Konsentrasi garam - garam jumlahnya relatif sama dengan setiap contoh air atau air laut, sekalipun pengambilannya dilakukan di tempat yang berbeda. Salinitas diukur dalam gram mineral padat dalam 1 kilogram air laut, atau bagian per seribu, yang kita tulis sebagai o/oo. Selain $\mathrm{Ph}$ dan Salinitas parameter kimia lainnya adalah kandungan logamlogam di dalam air tanah tersebut, baik yang bersifat toksik maupun esensial.

\section{Besi}

Besi ( $\mathrm{Fe}$ ) adalah elemen yang banak di batuan dan merupakan salah satu elemen kimia yang dapt ditemuai pada hampir setiap tempat di bumi, pada lapisan geologi dan semua badan air. Berdasarkan pengamatan di lokasi kegiatan Kuwaru, sarana prasarana sanitasi, khususnya air bersih yang memenuhi persyaratan belum dikembangkan. Keluhan yang disampaikan berkaitan dengan air bersih adalah air yang berbau amis, keruh/ berwarna kekuningan atau awalnya air jernih setelahdibiarkan ada endapan kuning kecoklatan, dan adanya noda-noda pada peralatan saniter. Dari data sekunder dan data primer, air tanah yang dikonsumsi penduduk/masyarakat Dusun Kuwaru mengandung Fe 0,3 - 2 mg/l dan Mn 0,05-1 mg/l. Fluktuasi kandungan Fe dan Mn ini tergantung pada lokasi sumur dan musim, dimana pada musim kemarau umumnya kandungan Fe dan Mn lebih tinggi dibandingkan saat musim penghujan. Hal ini logis terjadi, mengingat air tanah yang digunakan adalah sumur air tanah dangkal yang sangat dipengaruhi oleh musim. Pada saat analisa, tingginya kandungan Fe ditunjukkan oleh timbulnya warna merahkeunguan dan Mn ditunjukkan oleh timbulnya arna merah kecoklatan 1.(Susetyoningsih, Retno,2013)

\section{Filtrasi Keramik}

Filtrasi adalah proses pemilihan atau penyaringan air baku melalui media berbutir yang poros. Selama melalui media tersebut terjadi pemisahan atau reduksi kandungan material tersuspensi dan koloid, bakteri dan organisme lainnya,dan mengubah unsur-unsur kimiawi air melalui mekanisme filtrasi yang berlangsung di sepanjang filter bed. Pada saat ini terdapat trend baru mengenai piranti 
filter alam kemasan, salah satunya adalah menggunakan teknik membran. Adapun teknik atau proses membran memang beraneka jenis, antara lain: Reverse osmosis,elektrodialisis, Membran transport tergabung,dialisis, nanofiltrasi, ultrafiltrasi dan mikrofiltrasi. Mekanisme filtrasi dalam proses filtrasi yakni mekanikal straining, adsorpsi, aktifitas kimia, aktifitas biologi dan sedimentasi. Bahan pembuat keramik antara lain lempung, kaolin, pasir, feldspar. Dan proses pembuatan keramik meliputi pencetakan,pengeringan, dan pembakaran. (Jannah, 2009)

Filtrasi keramik baik menggunakan panci atau elemen filter berbentuk lilin, telah digunakan secara tradisional di banyak Negara untuk mengolah air minum di tingkat rumah tangga. Filter keramik telah diproduksi secar local dan komersial saat ini. (Herlambang, Ari, 2001)

\section{METODE PENELITIAN}

Penelitian ini menggunakan pendekatan ekperimenetal yaitu dengan menganalisa parameter kualitas air hasil filtrasi dengan saring keramik. Penelitian ini dilaksanakan di Pantai dan dan Dusun Kuwaru, Srandakan, Bantul. Dalam penelitian ini variabel bebasnya adalah saringan keramik dan variabel terikat adalah Parameter Fisik, kimia dan biologi

Tahap pengumpulan data dan pengujian air :

(1) Data primer dilakukan dengan pengambilan dan pengukuran kualitas air sumur warga sebelum dan sesudah filtrasi dengan keramik.

(2) Pengambilan sample air yang akan diuji kualitas airnya di laboratorium dilakukan terhadap 3 lokasi sumur.

(3) Pengukuran kualitas air akan dilakukan dengan 3 kali penyaringan dan 3 kali pengukuran dari 3 sumur yang telah ditentukan pengambilan sampelnya agar mewakili pengujian.

(4) Saringan keramik dicuci dahulu menggunakan air aquades,. Saringan keramik yang digunakan adalah saringan keramik diproduksi di Plered Purwakarta Saringan keramik pada penelitian ini mengikuti rancangan saringan keramik dari Resource Development International -Cambodia (RDIC), dimana elemen dari saringan terbuat dari lempung halus, bahan pengisi berupa sekam padi dan air yang dibakar dan setelahnya dilapisi larutan perak nitrat.

(5) Setelah kondisi siap tercapai, air tanah dialirkan ke dalam masing masing saringan dengan kapasitas 5 liter.

(6) Air hasil olahan keluar melalui rembesan dari saringan,dan ditampung untuk dianalisis. Luaran dari tahapan ini adalah kondisi kualitas air di lapangan dan hasil filtrasi saringan keramik dilengkapi dengan foto dan dokumentasi, hasil pengujian kualitas air di laboratorium terhadap sample air sebelum dan sesudah dilakukan filtarasi

Berikut ini adalah alat dan bahan yang digunakan dalam proses penelitian antara lain: Saringan keramik dan perlengkapannya, Ember, jerigen, dll., Botol sampel palstik, Botol sampel Kaca, Alat Pengukur kualitas air, Sampel Air Tanah.

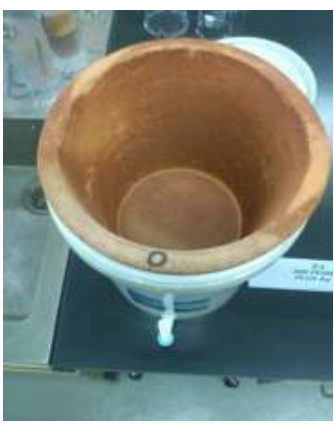

Gambar 1. Saringan Keramik

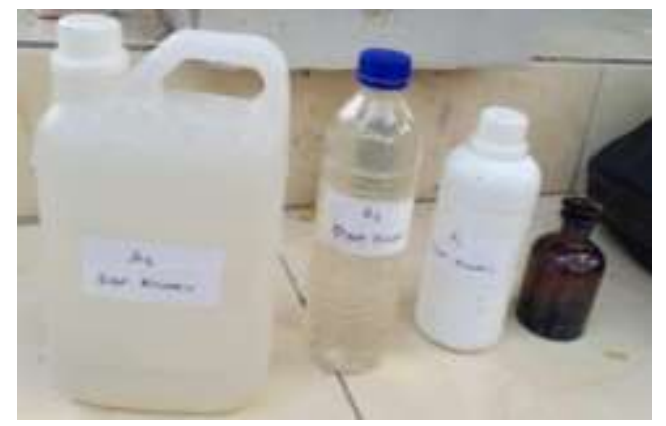

Gambar 2. Wadah Sampel

\section{HASIL DAN PEMBAHASAN}

Saringan keramik yang digunakan berjumlah 3 buah yang memiliki keamampuan merembeskan air 5 liter dalam waktu 3 jam atau kecepatan permeabilitas 1,667 lt/jam. 


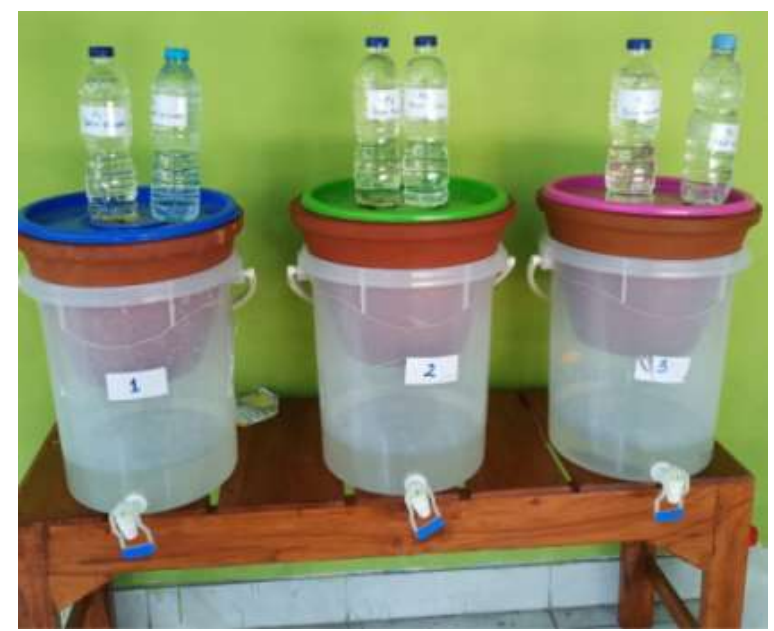

Gambar 3. Filtrasi dengan filter keramik

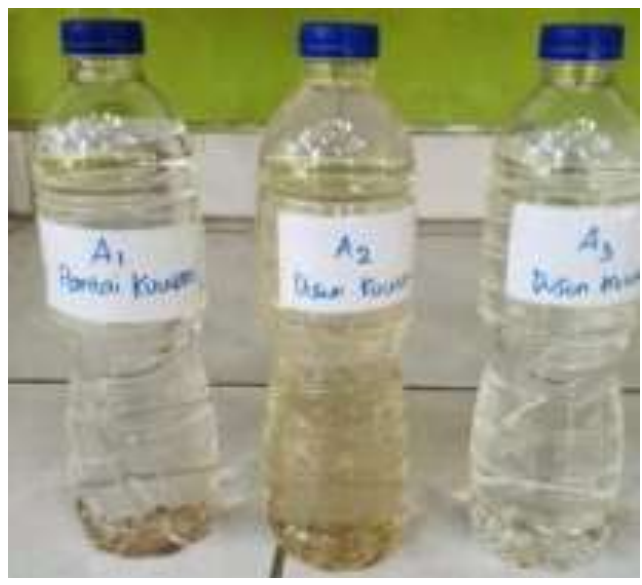

(a)

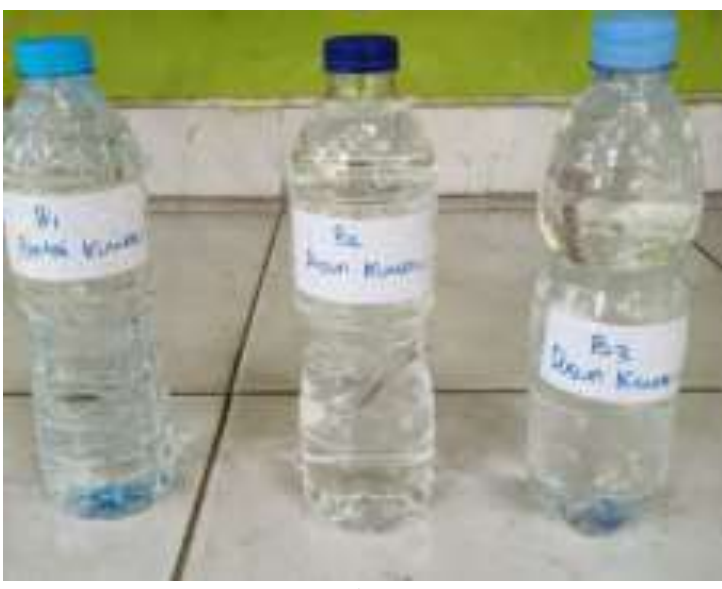

(b)

Gambar 4. Hasil Filtrasi dengan filter keramik

Berikut perbandingan beberapa parameter kualitas air sebelum dan sesudah penyaring dibandingan dengan Permenkes No.492/2010 tentang standar air minum

(1) Parameter Fisik

(1.a.) Kekeruhan

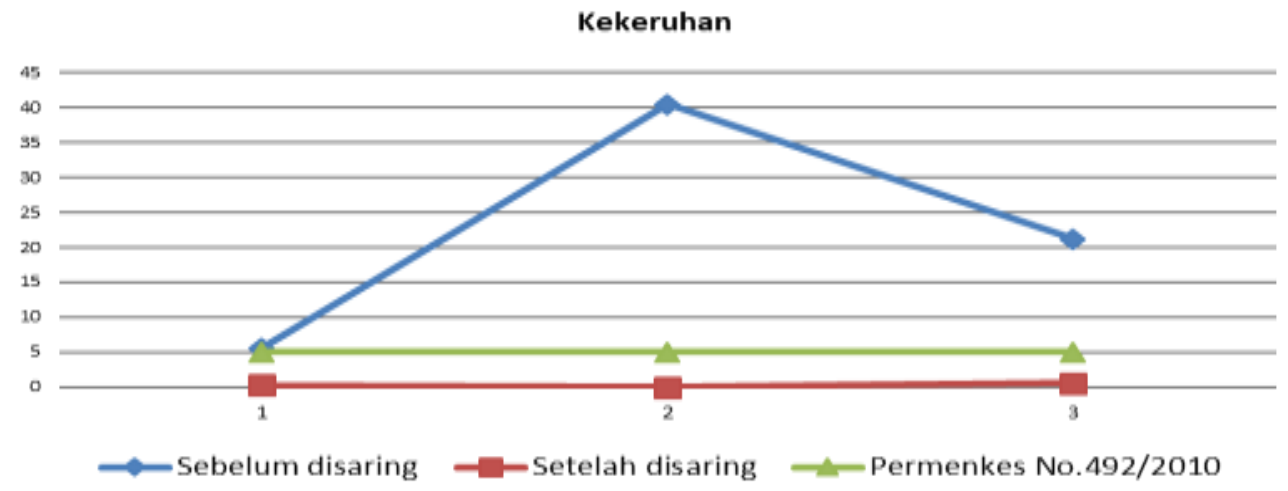

Gambar 5. Grafik Parameter Kekeruhan

( sumber: hasil analisis, 2019) 


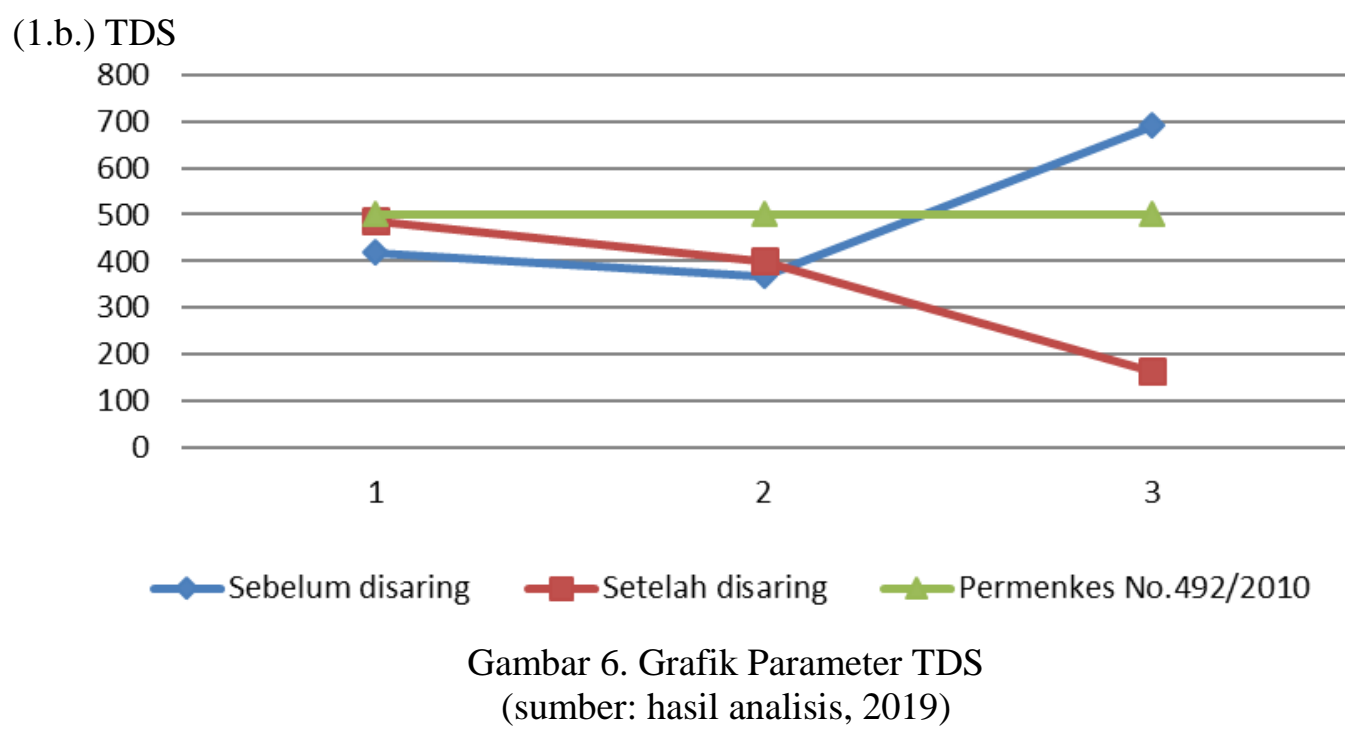

\section{(2) Parameter Kimia}

(2.a.) $\mathrm{pH}$

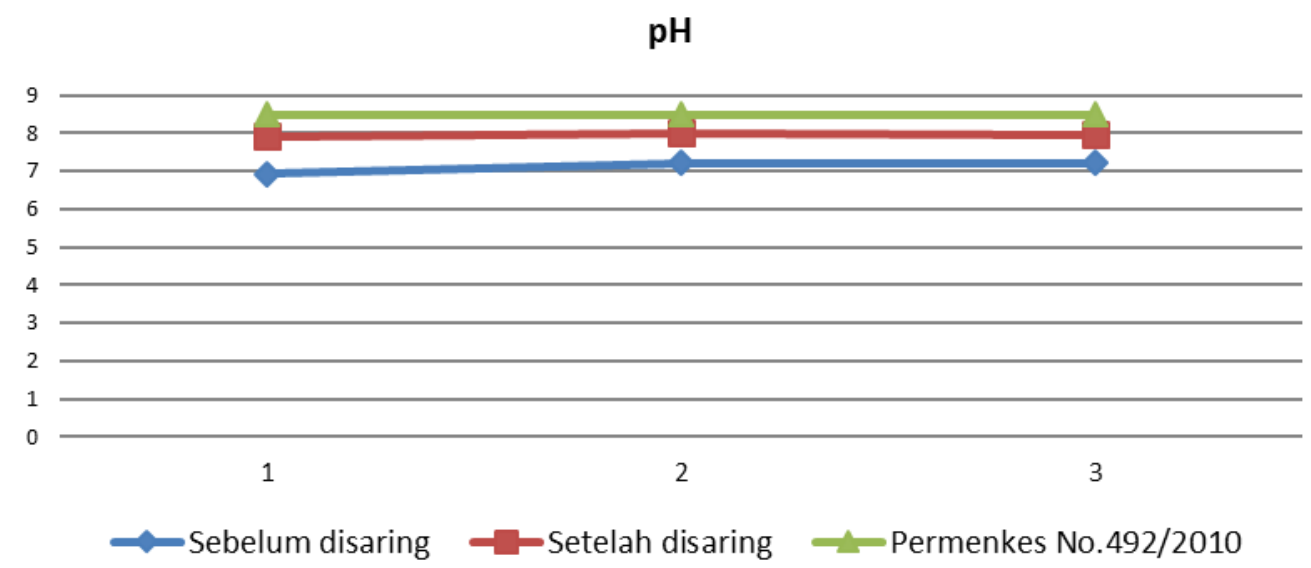

Gambar 7. Grafik Parameter $\mathrm{pH}$

(sumber: hasil analisis, 2019)

(2.b.) Nitrat

Nitrat (NO3-)

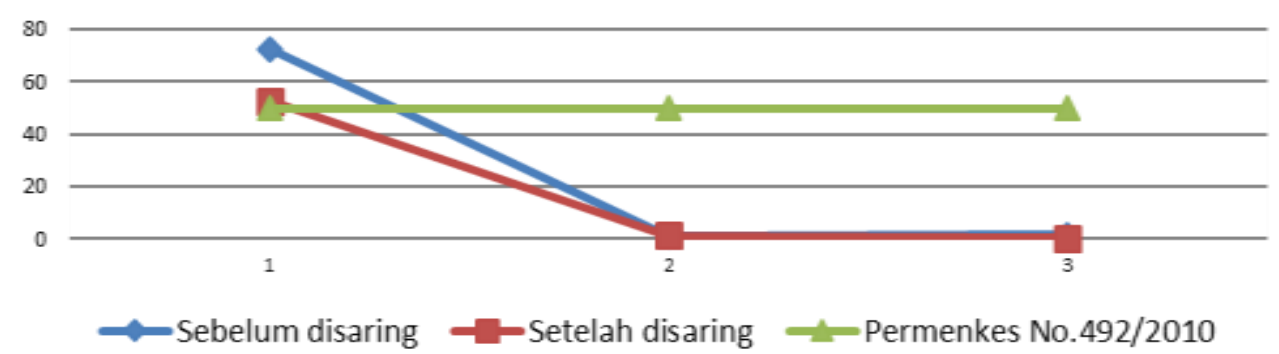

Gambar 8. Grafik Parameter Nitrat

(sumber: hasil analisis, 2019) 
(2.c.) Nitrit

Nitrit (NO2-)

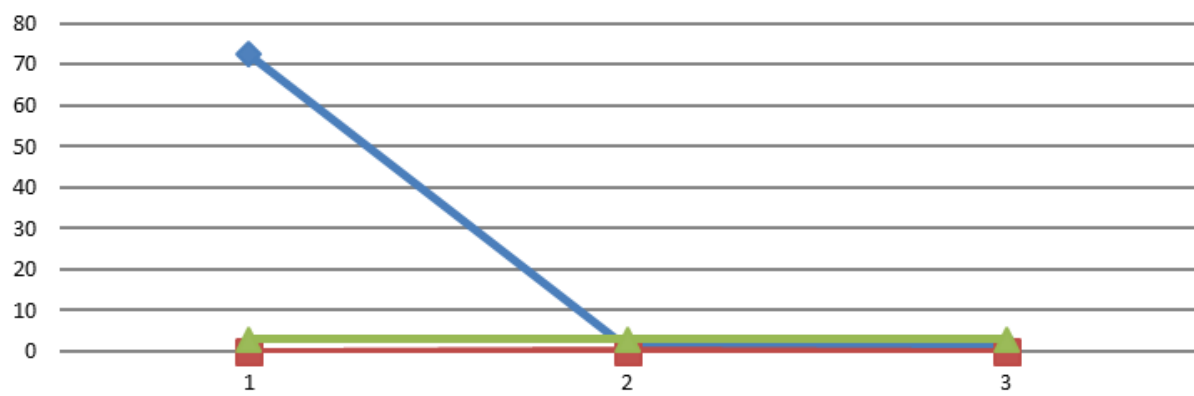

$\longrightarrow$ Sebelum disaring $\longrightarrow$ Setelah disaring $\longrightarrow$ Permenkes No.492/2010

Gambar 9. Grafik Parameter Nitrit

(sumber: hasil analisis, 2019)

(2.d.) Kesadahan

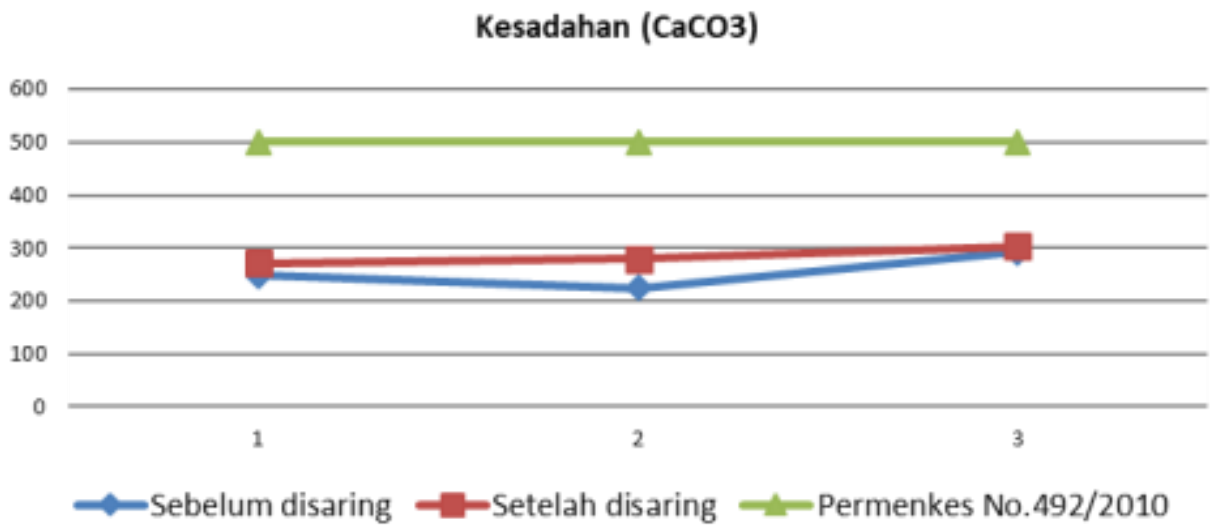

Gambar 10. Grafik Parameter Nitrit

(sumber: hasil analisis, 2019)

(2.e) Zat Organik

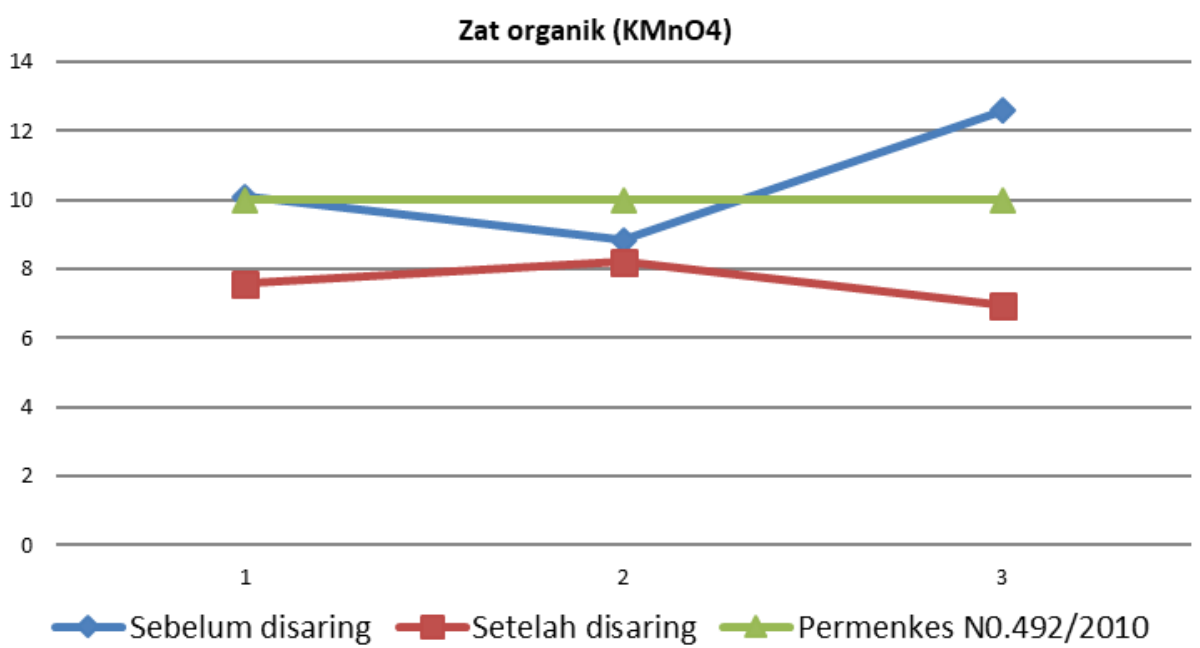

Gambar 11. Grafik Parameter Nitrit

(sumber: hasil analisis, 2019) 
(2.f.) Besi (Fe)

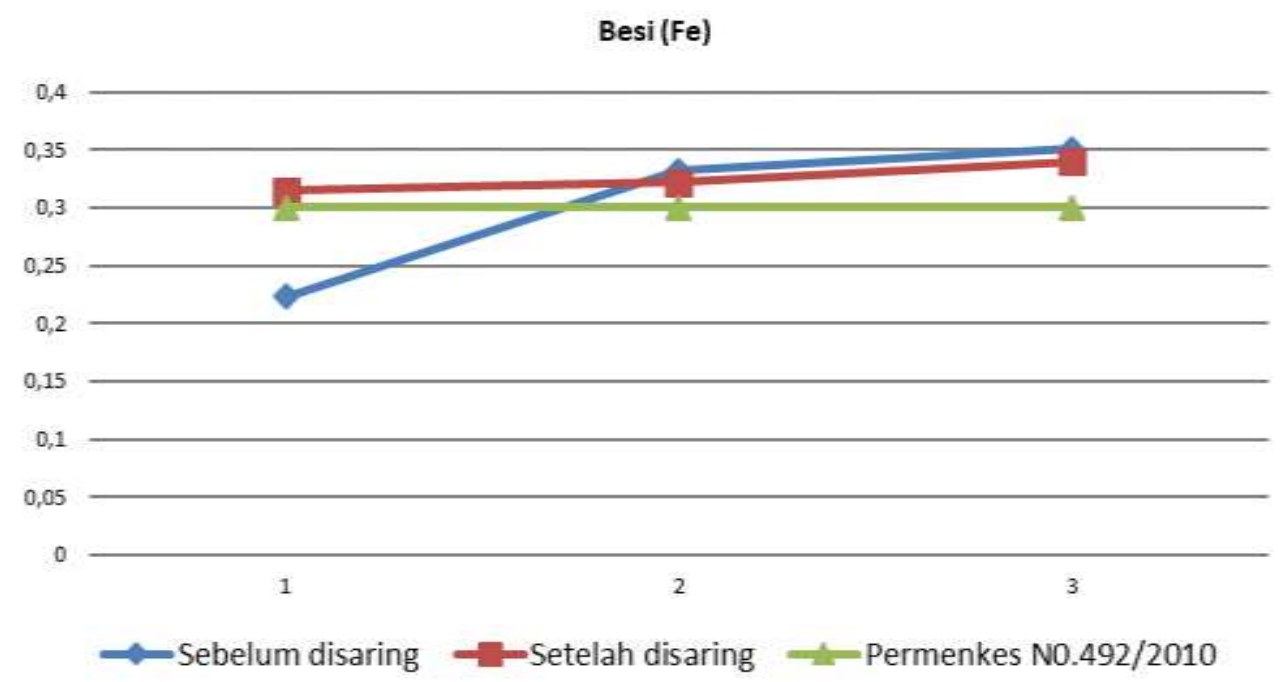

Gambar 11. Grafik Parameter Besi

(sumber: hasil analisis, 2019)

\section{(3) Parameter Biologi}

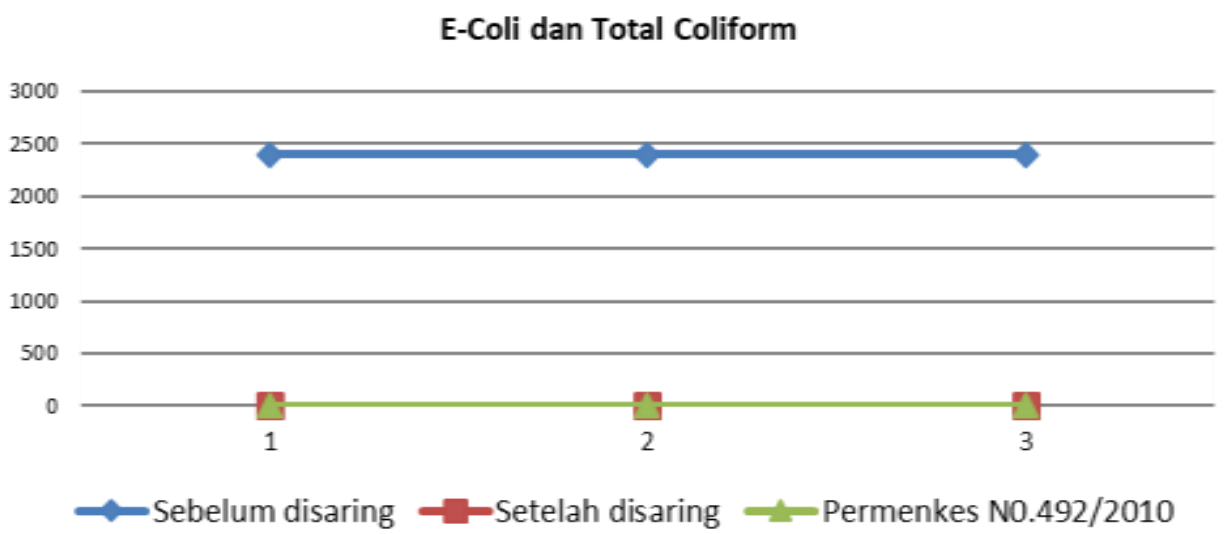

Gambar 12. Grafik Parameter Nitrit

(sumber: hasil analisis, 2019)

Dari hasill uji laboratorium diperoleh hasil sebagai berikut:, Kekeruhan, TDS, Ph, Nitrat, Nitrit, Kesadahan sebelum disaring jauh diatas ambang batas setelah disaring sudah di bawah ambang batas . Untuk Parameter Besi (Fe) sebelum dan sesudah penyaringan masih di atas ambang batas, sedangkan Parameter e-coli dan coliform setelah disaring turun drastis dari > 2400 MPN/100 menjadi >3 MPN/100 meskipun masih di atas ambang batas yaitu 0 .

\section{KESIMPULAN DAN SARAN}

\section{Kesimpulan}

(1) Laju infiltasi rembesan pada keramik $1.67 \mathrm{lt} / \mathrm{jam}$ atau $4,63 \times 10^{-5} \mathrm{lt} / \mathrm{dt}$

(2) Hasil Uji lab:

(a) Kekeruhan , TDS,Ph , Nitrat, Nitrit, Kesadahan, Zat Organik Sebelum disaring jauh diatas ambang batas setelah disaring sudah di bawah ambang batas

(b) Parameter Besi (Fe) Sebelum dan Sesudah penyaringan masih di atas ambang batas

(c) Parameter e-coli dan coliform setelah disaring turun drastis dari $>2400$ MPN/100 menjadi $>3$ MPN/100 meskipun masih di atas ambang batas yaitu 0

(d) Penyaringan atau filtrasi langsung dengan keramik tidak dapat menurunkan kadar atau kandung besi $(\mathrm{Fe})$ dalam air, sehingga saringan fiter dengan jeniss claypot kurang efektif untuk penyediaan air minum yang khusunya di Pantai di Kuwaru dan Dusun Kuwaru, Srandkan, Bantul Yogyakarta 


\section{Saran}

(1) Perlu dilakukan inovasi model filter keramik yang lebih efektif dan efisien karena filter yang digunakan saat ini kapasitas tidak terlau besar maksimal hanya 5 liter. Untuk waktu penyaringan juga memkan waktu yang cukup lama karean kecepatan peremeabilitasnya juga kecil.

(2) Perlu metode lainnya untuk menurunkan kada besi atau Fe karena dengan filtrasi keramik model clypot yang dipakai dalam penelitian ini belum secara efektif menurunkan kadar besi atau (Fe).

\section{DAFTAR PUSTAKA}

Effendi. H. 2003. Telaah Kualitas Air, Yogyakarta: Penerbit Kanisius

Herlambang, Ari, 2010, Teknologi Penyediaan Air Minum untuk Keadaan Tanggap Darurat JAI Vol 6 N0. 1,2010, http://ejurnal.bppt.go.id/ejurnal2011/index.php/JAI/article/view/310

Janah, Ni'matul dan Karnaningrum, Nieke, 2009. Penggunaan Filter Tembikar untuk Meningkatkan Kualitas Air Tanah Dangkal di Kelurahan Pogot Surabaya. Laporan Tugas Akhir (S1). Jurusan Teknik Lingkungan-FTSP ITS Surabaya, http://digilib.its.ac.id/public/ITS-Undergraduate11071-Paper.pdf

Retno, Susetyoningsih, AS, Arum Irene, 2013, Aplikasi Filtrasi Pasir Aktif Dalam Perbaikan Di Dusun Kuwaru, Srandakan, Bantul, Jurnal Riset Daerah, Volume.XII, No.2, Agustus 2013, http://jrd.bantulkab.go.id/2013

Sutrisno, C,T. 2006. Teknologi Penyediaan AirBersih. Jakarta: PT Rineka Cipta Suyono, 1993. Pengelolaan Sumber Daya Air. Fakultas Geografi Universitas Gadjah Mada. Yogyakarta. 